\title{
INDIGNACIÓN Y POLÍTICA EN LA MÚSICA \\ POPULAR ESPAÑOLA:EL IMAGINARIO \\ DE LOS VIDEOCLIPS INDEPENDIENTES ${ }^{1}$
}

\section{OUTRAGE AND POLITICS IN SPANISH POPULAR MUSIC: THE INDIE VIDEOCLIP IMAGINARY}

\author{
Héctor FOUCE \\ Universidad Complutense de Madrid \\ hector@fouce.net \\ Fernán DEL VAL \\ Universidad Nacional de Educación a Distancia
}

Resumen: Esta comunicación propone un análisis del videoclip La deriva, del grupo español Vetusta Morla. En un contexto de crisis política y social, observamos un proceso de politización de buena parte de los grupos de pop españoles más cercanos a la escena independiente. El análisis pretende esclarecer si esta politización se produce a través de las canciones en sí o a través del entramado intertextual (videoclips, entrevistas con los músicos, críticas periodísticas) que rodea las canciones.

Palabras clave: Música popular. Indie. Intertextualidad. Política. Videoclip. La deriva. Vetusta Morla. Política.

Abstract: This paper proposes to analyse the videoclip La deriva, from the Spanish band Vetusta Morla. In a context of political and social crisis, we see a process of politicization of much of the pop bands in the independent scene Spanish. The analysis aims to clarify if this politicization is produced through the songs itself or through the intertextual network (video clips, interviews with musicians, critical journalistic) surrounding the songs.

Key Words: Popular music. Indie. Intertextuality. Politics. Videoclip. La deriva. Vetusta Morla.

1 Este artículo forma parte de las actividades del proyecto de I+D “La construcción de los asuntos públicos en la esfera pública mediatizada" (CSO2013-45726-R). 


\section{INTRODUCCIÓN}

A finales de 2014 el periodista Víctor Lenore publica en la editorial Capitan Swing su libro Indies, hípsters y gafapastas (2014) que suscita un notable eco mediático en torno a la crítica de ese estilo musical, al que acusa de ser "la banda sonora de la clase dominante". Los argumentos de Lenore se centran en que el indie ha cultivado el individualismo, la negación de proyectos colectivos, la ausencia de temas sociales o políticos en sus letras y ha puesto su música al servicio de las marcas comerciales. Los músicos y oyentes de indie, clases medias urbanas, clases creativas, no solo evitan comprometerse sino que cultivan la ironía y el elitismo para marcar su pretendida superioridad intelectual, que en el fondo es una huida hacia delante para no reflexionar sobre su precariedad vital y laboral, la falta de capital económico suplido con un notable capital simbólico en forma de consumo desaforado de novedades culturales y musicales de usar y tirar (Bourdieu, 1988).

El texto de Lenore viene prologado por Nacho Vegas, que ya en 2011 había escrito la canción Como hacer crack y había sido uno de los impulsores de la Fundación Robo, un colectivo de músicos, todos procedentes de grupos indies, que estaba produciendo canciones de clara orientación política. En 2014 Nacho Vegas publicó su disco Resituación, de claro trasfondo político, elegido por buena parte de las publicaciones musicales (consideradas por Lenore cómplices necesarios, cuando no inspiradoras, de la apatía y el elitismo) como uno de los mejores del año.

¿Se está produciendo una repolitización del mundo de la cultura como consecuencia de la crisis y de las propuestas colectivas de reacción o simplemente la política se ha convertido en un elemento más de la impedimenta de la modernidad urbana? ¿Qué concepto de política se maneja en este proceso, en todo caso? ¿Cómo entronca este proceso de creación de nuevos discursos políticos con otros estilos y géneros de la música popular en España y cómo se relaciona con las condiciones de producción de la música en la actualidad? Este texto trata de dar respuesta a estas cuestiones en la convicción de que el mundo de la cultura anticipa tendencias sociales (Hernández, 2014: 14).

A lo largo del último año hemos tenido la ocasión de presentar nuestro trabajo en diferentes espacios académicos. En las discusiones quedó clara la dificultad de abordar el estudio de una escena musical debido a la multiplicidad tanto de actores como de textos. Las canciones construyen un discurso que se solapa con el del videoclip, las interpretaciones de los oyentes nacen tanto de su escucha y de su consumo de imágenes como de la lectura de otras interpretaciones, las del propio artista a través de entrevistas, las de los críticos al comentar los discos o conciertos, las de otros fans en las redes sociales. Como participantes en una escena, oyentes de una música, no construimos nuestra interpretación en el vacío sino en un eco de voces intertextuales. Cuando defendemos que la escena indie se está politizando del mismo modo que lo está haciendo la sociedad 
española en general, es necesario aclarar qué discursos analizamos para sustentar nuestra interpretación. No siempre las canciones y los vídeos responden de forma obvia a las lecturas propuestas por los propios músicos. Por ello, hemos entendido necesario hacer un análisis en profundidad de una canción representativa de ese giro político en la escena indie. Hemos escogido La deriva, de Vestusta Morla, para poder presentar un análisis detallado. Otros temas, como Polvorado o Actores poco memorables, de Nacho Vegas, o Ratonera, de Amaral, serán analizados más adelante en el curso de la investigación.

\section{DISCURSO, POLÍTICA, MÚSICA}

Si bien la sociedad española parece haberse politizado a raíz del 15-M, la crítica musical se ha mostrado contraria a que esta politización permee la música popular. Recientes investigaciones sobre el canon estético de la crítica musical española (Noya, Val y Pérez Colman, 2014) muestran que, eso que Bourdieu llamaba "arte social", una forma de entender la producción artística bajo el influjo del realismo y del compromiso político, queda fuera de ese canon. Escenas musicales como los cantautores, el rock urbano, el punk, el rock radikal vasco o la rumba, caracterizadas por su denuncia social y política, son despreciadas, al menos estéticamente.

El indie español, en sus orígenes, era una escena despolitizada, si entendemos por politización el que incluyesen en sus letras temas sobre partidos políticos, sobre desigualdad social, sobre historia de España... Sin embargo, si atendemos a su relación con la industria, ahí si vemos prácticas políticas (el ejemplo del Inquilino Comunista, rechazando firmar por multinacionales, la creación de sellos y fanzines ante el poco caso de los grandes medios...). La actitud de la escena hacia lo político viene reflejada en la canción Vuelve la canción protesta, que escenifica el rechazo a las propuestas de una generación de cantautores que emerge en los 90 en paralelo a la escena indie. "Políticos y banqueros tiemblan, vuelve la canción protesta", cantaba el grupo de Granada. Tres lustros después, parte de los miembros de ese grupo, agrupados ahora bajo el nombre de Grupo de Expertos Solynieve, recuperan una metáfora clásica de los cantautores, la del amanecer que rompe la oscuridad y que se espera con ansiedad (Fouce, 2006), en su canción La nueva reconquista de Graná. La letra establece un paralelismo entre los árabes expulsados en 1492 y los afectados por la crisis económica y política.

¿Qué ha ocurrido para ese cambio en la forma de conceptualizar la política? Sin duda el 15-M ha cambiado la forma de entender lo político. De alguna manera la cultura política de los españoles estaba mediada por el bipartidismo, por estereotipos políticos construidos en la Transición. El 15-M ha roto esos estereotipos, ha modernizado ideas y ha desterrado viejos clichés sobre hablar de política. Existe un consenso de partida sobre el que establecer un nuevo discurso político: "no nos representan". 
El artista en el que se ha focalizado el cambio de paradigma en el indie es Nacho Vegas. De su época tortuosa, maldita y adicta, Vegas ha pasado a textos directos, casi panfletarios, si bien su primera aproximación a lo político fue la insinuante Cómo hacer crac (2011), que comienza con el sonido de una manifestación de fondo. Texto sobre la soledad y la falta de apoyos. Pero la letra gira en un momento. Algo ha hecho "crac", algún dique o alguna barrera se ha roto:

Te informan de que han desarticulado

A la cúpula de la CEOE,

$Y$ de que solo habrá un nuevo principio

Una vez consumado el fin.

Y una niña susurra a tu oído

Que han desahuciado a la familia Botín

Y que han cambiado el significado

De algunos verbos como disfrutar.

$Y$ en la calle se hace un gran silencio,

Pero si escuchas bien oirás un crac.

En toda España solo suena un crac.

En occidente solo se oye un crac.

$Y$ si esto no es el fin,

Si esto no, no, no es el fin,

Si esto no, no, no es un final

Entonces es la bomba que va a estallar.

El paulatino proceso de politización de la escena indie ha sido recibido por la crítica con escepticismo o animadversión. El ejemplo más claro es Nacho Vegas. Santo y seña para Rockdelux, la revista que ha articulado la escena independiente en los últimos lustros, su giro político no gusta en la publicación que, de manera premeditada elabora una crítica muy dura del disco, junto con una entrevista muy agresiva con el cantautor.

Jesús Rodríguez Lenin (2014) comenzaba así la entrevista a Vegas: “...el asturiano ha perdido su lírica para caer en el panfleto y, donde antaño había melodías de terciopelo, ahora hay músicas facilonas". Vegas se defiende: "No es que haya cambiado yo, es que ha cambiado el mundo alrededor. El 15-M supuso un cambio de actitud entre muchísima gente".

Pero hemos elegido a Vetusta Morla porque es sin duda un grupo de notable éxito popular. A pesar de su sonido y de que son habituales figuras en los carteles de los festivales de la escena indie, se les discute a menudo su adscripción a la escena. Hecho llamativo en tanto en cuanto pocos grupos funcionan de una manera tan autogestionada 
como este. Es precisamente este cuestionamiento por parte de la escena indie que resulta interesante hacer un acercamiento a las lecturas políticas de sus canciones.

El músico valenciano Maronda (Guillot, 2011) fue uno de los primeros en tratar la cuestión de la política desde el indie:

Creo que la gente en el indie no se atreve a hablar de política, es como un tema tabú, que parece destinado a grupos como La Polla Recordso Elúltimo Ke Zierre, y que si lo mencionas en el contexto de un grupo con referencias indies parece fuera de lugar, como si no tocara (...) Igual si hablamos de Vetusta Morla o esta gente del sonido Inditex, puede ser que, más que de derechas, no se definan políticamente, o que sean producto de su tiempo, en que la gente joven no está acostumbrada a manifestar un compromiso político público.

Sin embargo, los medios recibieron el disco de Vetusta Morla, La deriva, incidiendo en su tono comprometido. "Vetusta Morla afina el tono reivindicativo y de denuncia social sobre los tiempos que corren" (Iraeta, 2014). "La deriva expresa el estado de ánimo de Vetusta Morla en los tiempos que corren, dominados por la palabra 'crisis', aunque con una esperanza en la posibilidad de reconducir el rumbo". "La ilusión y la esperanza es un hilo conductor del disco pese a venir de un naufragio que nos ha afectado a todos" (Diario Crítico, 2014).

El single de presentación del disco fue Golpe maestro: “Fue un atraco perfecto, fue un golpe maestro, dejarnos sin ganas de vencer (...) quitarnos la sed". Junto con La deriva evocan una atmósfera de pérdida, de expolio, de robo y represión, pero también de resistencia y esperanza: "Fue un atraco perfecto, excepto por esto: nos queda garganta, puño y pies. No fue un golpe maestro, dejaron un rastro, ya pueden correr. Ya vuelve la sed". Resulta difícil resistir la tentación de no colocar estas canciones en diálogo con su momento social y político: la crisis económica, las políticas de austeridad, el desmontaje de los servicios públicos, el 15-M, las mareas y los movimientos municipalistas...

\section{EL VIDEOCLIP COMO ESPACIO DE DENSIDAD REFERENCIAL}

Proponemos un análisis en profundidad de la canción La deriva y de su videoclip, que fue la tarjeta de presentación del disco. Fue dirigido por Juan Cavestany, que el año anterior dirigió Gente en sitios, una película de bajo presupuesto y notable éxito, especialmente entre la crítica y en los festivales. La estética de esa película, que retrataba de forma irónica personajes y elementos de la vida cotidiana, impregna también este videoclip. 
El videoclip se articula, como es habitual en el género, como un collage en el que se entrecruzan tres grandes relatos con una estética hiperrealista, de cámara en mano, enfatizando la proximidad y la naturalidad de la mirada del director. En él se entrecruzan tres grandes familias de imágenes que construyen relatos diferentes.

El primer relato es el de la experiencia cotidiana: un hombre en la consulta del dentista, niños corriendo en dirección al recreo en el colegio, coches y peatones circulando en la ciudad, trabajadores empujando trozos de carne en una instalación industrial, interior de vagones del metro... El segundo relato corresponde a un canal de pruebas de barcos. "Cuando hablé con el grupo, lo primero que mencioné fue una asociación totalmente arbitraria, la primera imagen que me había a la cabeza: los canales de barcos de las películas de François Truffaut. Resulta que en Madrid había uno parecido", asegura el director. Las imágenes del canal de pruebas enganchan con los interiores industriales del relato anterior, pero también juegan el importante papel de articular la letra con las imágenes. Y el tercer elemento estructurante del videoclip es un cuerpo de baile, constituido por hombres y mujeres, que viste ropas cotidianas y en tonos apagados, ejecutando una coreografía o recibiendo las instrucciones del director en un espacio vacío que parece un almacén o un espacio industrial (lo que establece de nuevo una continuidad con escenarios que pertenecen a los otros dos relatos).

La letra de la canción es, del mismo modo que las imágenes, fragmentaria y no narrativa. El estribillo, que en las canciones pop tiende a repetirse sin cambios, va transformándose en cada una de las tres veces que aparece. En cualquiera de sus tres diferentes formas aparecen ligados el timón y la deriva: se crea así un cronotopo mínimo que vincula la canción al mundo de los barcos y el mar, esa "asociación arbitraria" que refiere el director.

Puesto que lo que nos interesa es discutir una posible lectura política de esta canción, merece la pena detenerse en la construcción del enunciador y en cómo va cambiando según avanza la misma. Las tres primeras estrofas arrancan en primera persona y en pasado: "he tenido tiempo, he enterrado, he prendido, he escuchado...". Solo después del primer estribillo aparece brevemente una segunda persona: "Has tenido pulso para engancharme/ alistado en ejércitos suicidas/ Me adentré en el bosque y no encontré al vigía". Suceden a esta breve estrofa dos versiones diferentes del estribillo: ambas arrancan en modo impersonal ("habrá que inventarse"). ¿Debe entenderse esta elisión del sujeto como un rasgo de individualidad o como una forma de apelar indirectamente al colectivo? Buena parte de las discusiones que hemos sostenido en torno a las lecturas políticas de esta canción critican esta ambigüedad, entendida como una ausencia de toma de postura por parte del grupo en un contexto en el que las llamadas a la acción colectiva marcan la acción política. Los nuevos partidos se llaman Podemos, Ganemos, Barcelona en común... Y del mismo modo este modo impersonal evita constituir un 
tiempo para la acción: Ahora Madrid, el partido instrumental que logró hacerse con el Ayuntamiento de la capita, apela a una urgencia para la acción política, pero en el discurso de Vetusta Morla este "habrá" elimina también el tiempo de la acción, lo pospone a un futuro que se evita definir.

Lo impersonal cede paso a la individualidad en el segundo estribillo ("no quiero timón en la deriva. / Cada cual que tome sus medidas"). De nuevo, la primera persona es la que decide lo que quiere, y el siguiente verso ya explicita que debe ser cada uno quién decida qué acciones tomar. Si la canción acabase aquí, la "esperanza en la deriva" que cierra el estribillo derivaría de una toma personal de postura que simplemente nacería de la sensación de estar en tierra de nadie y de la obligación de buscar nuevos rumbos que la canción construye. Pero el tercer estribillo ejecuta un giro hacia la acción colectiva: "Habrá que inventarse una salida / Que el destino no nos tome las medidas". Por primera vez en toda la canción, estamos ante una primera persona del plural, un nosotros que somos invitados a "buscar una salida". Es, evidentemente, una invocación colectiva bien débil, no comparable a la del Polvorado de Nacho Vegas que canta "polvo somos, lo sabemos, y en pólvora nos convertiremos", acompañado por un coro. El sujeto enunciador es aquí el colectivo, mientras que en La deriva es un sujeto individual que solo en una breve ocasión es capaz de invocar a lo colectivo, y más en términos de resistencia, de evitar algo, que en términos proactivos.

No deja de llamar la atención lo notablemente diferente de las dos metáforas: la deriva implica falta de control, mientras que la pólvora siempre ha sido la metáfora de la acción directa, capaz de cambiar el status quo aunque sea de forma violenta. Pero en la canción de Vetusta Morla aparece un elemento equivalente: la gasolina. "Ya cambié el balón por gasolina" remite a un cambio temporal y a un cambio de actitud: el niño se hace mayor, el tiempo lúdico da paso al tiempo de la destrucción, ya que esa gasolina está ligada a "he prendido el bosque al incendiar la orilla". Consecuencias exageradas de una acción simple. Consecuencias probablemente no previstas. ¿Llamada a la reflexión antes de lanzarse a actos de protesta? En todo caso, la imagen de una tierra en llamas, observada desde un barco, remite a una mitología aventurera del punto de no retorno: ya no hay una tierra firme que ofrezca un punto de llagada o de partido, ahora se está a merced de la corriente. Juanma Latorre, guitarrista del grupo, ahonda en esta interpretación y en sus ambivalencias: "Eso de estar en un rumbo diferente a veces es negativo pero también positivo, y ahí aparecen sentimientos encontrados, de llorar la pérdida del rumbo que pensabas que era bueno, pero también esperanza por poder ir a un sitio mejor" (Diario crítico, 2014).

Un último elemento del análisis de la letra de la canción es la construcción del antagonista. Puesto que la canción no tiene una estructura narrativa y que se recurre al estilo impersonal, no hay espacio para construir un antagonista. Sólo en la tercera 
estrofa aparece una referencia a esta figura "he escuchado el ritmo de los feriantes/ poniendo precio a mi agonía". Escuchada la canción en el contexto de las políticas de austeridad y del rechazo a la actual clase política, es difícil sustraerse a la tentación de evocar eslóganes como "no somos mercancía en manos de políticos y banqueros" o "paremos la Europa de los mercaderes". El feriante aparece como la encarnación máxima del comerciante, ajeno a vinculaciones territoriales o comunales, ligado siempre a un mundo en el que la maravilla y la fantasía se cruzan con el timo y el engaño. Muy en línea con las representaciones de la crisis del "capitalismo de amiguetes", en el que personajes y empresas que se presentan como solventes y profesionales se comportan como jugadores sin escrúpulos que actúan ajenos a las posibles consecuencias de sus actos. Aunque estos supongan dejar a gente en la calle o sin asistencia sanitaria (el precio que pagan por la agonía al que se refiere la canción).

Pero en esta ocasión nos interesa no sólo una canción, sino el videoclip. Aquí, la música se convierte en un texto que interacciona con la imagen para crear un nuevo sentido. Como explica Sibilla (1999: 21) "la canción está dotada de un sentido de origen: sentido que la mezcla con la imagen puede interpretar, metaforizar, deformar, revolver, pero de la que no puede prescindir". De ahí, la necesidad de analizar la canción. No podemos olvidar que la música popular siempre ha ido ligada a las imágenes: las ventas de discos de una estrella como Elvis Presley palidecen ante el número de espectadores de sus películas. De hecho, las generaciones más jóvenes escuchan música masivamente desde YouTube, ligada por tanto a las imágenes en movimiento.

Nuestra lectura del videoclip está marcada sin duda tanto por el interés hacia el género musical como por mis posicionamientos políticos. Como enunciatarios, leemos desde una posición espacial, temporal y axiológica. Creo que la intención del director y del grupo es precisamente apelar a situaciones de lectura similares a las mías, de ahí que defienda la validez de mi análisis más allá de las percepciones personales.

Me detendré en tres momentos del videoclip para ilustrar la interacción de la imagen y el sonido de cara a lograr la interpretación que aquí se defiende. El primer momento (0.40) es el arranque de la voz tras la introducción instrumental: durante las primeras estrofas vemos, en montaje paralelo, una clase en un colegio y la salida de los niños al patio, las explicaciones del director del cuerpo de baile mientras los bailarines se miran incómodos y extrañados y por último imágenes del agua del canal de barcos en calma. Cuando entra el estribillo estos momentos preparatorios de actividad dan paso a la danza y a las actividades varias del relato de la experiencia cotidiana. Y cuando termina el estribillo (1.55) arranca un solo de guitarra con una línea melódica ascendente mientras vemos como se encienden las luces en el canal, los niños salen corriendo al patio y un coche circula frente al arco iris. 
El siguiente tramo de imágenes se inicia en 2.25. Mientras la voz ejecuta los estribillos 2 y 3, la dinámica de la canción va variando. La batería desaparece durante la primera línea del estribillo para ir reapareciendo poco a poco. Cuando se inicia el tercer minuto comienza un crescendo instrumental acompañado por un montaje más acelerado de las imágenes: un avión despega mientras alguien se agarra fuerte de los brazos del asiento, una mano se cierra sobre el pasamanos de unas escaleras mecánicas, otras aprietan las sábanas, otras manos de diferentes personas alcanzan las barras de sujeción del metro. En el canal empiezan a crearse olas. Son todos planos detalle que alternan con un movimiento del cuerpo de baile en el que un miembro de la pareja se sube sobre la espalda del otro que está a cuatro patas. El personaje del dentista aprieta los ojos de dolor y en 3:23 coge el brazo de la dentista en busca de consuelo.

El bloque final de imágenes se inicia con un plano subjetivo que muestra a la embarcación dirigiéndose hacia las olas mientras el último estribillo canta "habrá que inventar una salida". Este es el momento en el que las guitarras suenan más distorsionadas. Cuando la voz canta "hay esperanza en la deriva" la cámara gira en torno a una niña, parada en medio del patio y rodeada de compañeros que corren, que mira a la cámara con calma. Ese plano da paso al de una joven, también parada en medio del movimiento del cuerpo de baile, con la mirada también relajada, en primer plano. La multitud corre hacia ella y parece que va a ser arrollada, pero es agarrada por un compañero y se incorpora al movimiento del grupo. La imagen final del video, mientras las guitarras se desvanecen, es una imagen del canal ya en calma.

La alternancia de los relatos y la superposición del registro verbal, el sonoro y el visual juegan con lo que Hebdige (cit. en Sibilla, 1999: 22) ha llamado "densidad referencial": a través de la recreación de la atmósfera evocada en la canción y de la multiplicación de los aspectos y puntos de vista en juego se sustituye la coherencia narrativa de otros géneros visuales.

Como es norma en el videoclip, la forma rítmica de la canción marca la velocidad de las imágenes y funciona como "una rejilla rígida en la que insertar las partes" (Sibilla, 1999: 23). Pero lo novedoso de este vídeo es que no existe sincronización de ningún otro tipo: mientras que en general se recurre al encuadre instrumento y al encuadre voz (mostrar bien a los músicos, bien la imagen del cantante en la performance) como forma de articularlos elementos eclécticos, aquí se renuncia a la presencia de los músicos para construir un texto que funciona como un mosaico sin un elemente interno que aglutine las imágenes.

Es por tanto el espectador quien debe establecer la coherencia del texto fragmentado. La lectura que yo propongo coincide con la que hace Gonzalo de Pedro (2014) en su reseña del videoclip: 
Cavestany ha construido una oda a cosas que ya no están de moda, y que parecen revolucionarias: el trabajo, la amistad, la confianza, y la fuerza del colectivo. Frente a las oleadas de inmoralidad que nos invaden, La deriva de Cavestany es un canto a la vida en común, un homenaje al trabajo (y al trabajador, ahora que ya no hay obreros, solo emprendedores), a la solidaridad, a la importancia de apoyarnos y confiar los unos en los otros.

Este énfasis en el vínculo entre comunidad, trabajo y cuidado mutuo está en la base de muchos discursos intelectuales surgidos al calor del 15-M. Lo cotidiano, los espacios de la interacción casual no segmentados por edad, clase o posición económica aparecen como los espacios de la ciudadanía y de la democracia. Su reivindicación es una crítica al modelo de ciudad y de sociedad neoliberal que componen un individuo racional cuyas interacciones se miden en términos de eficiencia y ganancia (Rendueles, 2013). Lo político aparece ya no como el espacio de los partidos y las votaciones, sino como un modelo de construcción de vida en común y de participación discursiva en la vida pública. Así lo expresa Guillermo Galván, uno de los miembros de Vetusta Morla (Lenore, 2014a):

Vivimos un momento en el que parece que hablar de justicia y de derechos te convierte en un antisistema. Nosotros solo somos ciudadanos. Básicamente, quien hace música popular es un cronista. Estamos reflejando los problemas de la gente con la que tomamos café, los amigos, la familia y los conocidos. Creo que la fuerza de estas letras -las de Amaral, Nacho Vegas o las nuestras- es que llegan escritas por artistas que en principio no te esperas que las hagan. Si las firmaran grupos tipo Kortatu o La Polla Records no pasaría nada porque ya están etiquetados. Hablar contra políticos y banqueros entra en lo previsible de sus planteamientos. Ahora ciertos grupos estamos tomando decisiones que no tienen que ver con ser músicos, sino con ser personas. El 15M ha ayudado a que miremos más a nuestros vecinos y a nuestros barrios. Sentimos la necesidad de hacer algo, aunque no sepamos qué. O no lo sepamos bien del todo.

\section{CONCLUSIONES}

Las canciones son textos de la cultura contemporánea abiertas a la interpretación. El texto de una canción es muchas veces polisémico y su sentido final difícil de establecer. Pero la interpretación de la letra de una canción no se desarrolla en el vacío: establece 
una red intertextual con el propio sonido de la canción, con las imágenes del videoclip, con las declaraciones de músicos y críticos sobre su significado y, finalmente, interacciona con su contexto.

En este artículo hemos querido analizar la interrelación de una letra tanto con las imágenes que la acompañan en el videoclip como con su contexto histórico. En un momento de crisis política, en el que los partidos que han marcado la Transición parecen ceder terreno frente a otros emergentes, algunos surgidos de la confluencia de movimientos sociales contestatarios, existe un clima de opinión que pide una toma de postura por parte de los artistas. Si bien una parte de crítica musical se resiste a aceptar como válida una música explícitamente política, desde otra parte se reclama esa música política. De manera más interesante, como muestra la canción La deriva, se reclama el significado político de canciones que no hacen referencia explícita al asunto. Es precisamente aquí cuando interviene la red intertextual que rodea a la canción: la densidad de las imágenes, la propia personalidad del director del clip, las lecturas de los críticos y algunas declaraciones de los músicos en respuesta a su momento histórico crean el escenario para que una canción sea leída en clave de mensaje político.

\section{REFERENCIAS BIBLIOGRÁFICAS}

BOURDIEU, P. (1998). La distinción. Criterio y bases sociales del gusto. Madrid: Taurus.

DEL VAL RIPOLLÉS, F. (2014). Rockeros insurgentes, modernos complacientes: juventud, rok y política en España (1975-1985). Tesis doctoral.

FOUCE, H. (2006). El futuro ya está aquí: música pop y cambio cultural en España. Madrid:Velecio. DE PEDRO, G. (2014). "Juan Cavestany dirige La deriva, el nuevo videoclip de Vetusta Morla". En Sensacine.com http://www.sensacine.com/noticias/cine/noticia-18517841/[29/09/2015]. Diario crítico (2014). "La deriva de Vestusta Morla, un disco sobre "un naufragio que nos ha afectado a todos". Diario crítico http://www.sensacine.com/noticias/cine/noticia-18517841/ [29/09/2015].

GUILLOT, E. (2011). "Maronda: La política es un tema tabú en la escena indie". Efe Eme. http:// www.efeeme.com/maronda-la-politica-es-un-tema-tabu-en-la-escena-indie/[29/09/2015].

HERNÁNDEZ, E. (2014). El fin de la clase media. Madrid: Clave intelectual.

IRAETA, M. (2014). "Vetusta Morla - La deriva / estreno". Radio 3. http://radio3.rtve.es/ recomendaciones/2014/04/vetusta-morla-la-deriva-estreno.html [29/09/2015].

LENORE, V. (2014a). Indies, hipsters y gafapastas. Crónica de una dominación cultural. Madrid: Captán Swing.

(2014b). "Amaral se posiciona, Serrat y Sabina callan". El Confidencial. http://www. elconfidencial.com/cultura/2014-04-12/amaral-se-posiciona-serrat-y-sabina-callan_115741/ [29/09/2015]. 
NOYA, J.; VAL, F. y PÉREZ COLMAN, M. (2014). “'Autonomía, sumisión o hibridación sonora? La construcción del canon estético del pop-rock español". Revista Española de Investigaciones Sociológicas 145, 147-180.

RENDUELES, C. (2013) Sociofobia. El cambio político en la era de la utopía digital. Madrid: Capitán Swing.

RODRÍGUEZ LENIN, J (2014). “Dándonos de hostias (dialécticas). Rockdeluxe 327.

SIBILLA, G (1999) I/ videoclip nella Tv italiana. Roma: RAI. 